\title{
WPS3624
}

\section{PESTICIDE Poisoning OF FARM WORKERS: IMPLiCATIONS OF BLOOD TEST RESULTS FROM VIETNAM}

\author{
Susmita Dasgupta* \\ Craig Meisner \\ David Wheeler \\ Nhan Thi Lam \\ Khuc Xuyen
}

\begin{abstract}
World Bank Policy Research Working Paper 3624, June 2005
The Policy Research Working Paper Series disseminates the findings of work in progress to encourage the exchange of ideas about development issues. An objective of the series is to get the findings out quickly, even if the presentations are less than fully polished. The papers carry the names of the authors and should be cited accordingly. The findings, interpretations, and conclusions expressed in this paper are entirely those of the authors. They do not necessarily represent the view of the World Bank, its Executive Directors, or the countries they represent. Policy Research Working Papers are available online at http://econ.worldbank.org.
\end{abstract}

* The authors are, respectively, Senior Economist, Consultant, Lead Economist, Development Research Group, World Bank; Chief, Central Medical Laboratory of the Tien Giang Preventive Medicine Centre and Director, National Institute of Occupational and Environmental Health, Vietnam. We would like to express our appreciation to the medical research team of National Institute of Occupational and Environmental Health, Vietnam for their excellent field work and to Jostein Nygard, East Asia Environment Unit. 


\begin{abstract}
In this paper, we have assessed the incidence and determinants of pesticide poisoning among rice farmers in Vietnam's Mekong Delta. Blood cholinesterase tests suggest that the incidence of poisoning from exposure to organophosphates and carbamates is quite high in Vietnam. Using the medical test results as benchmarks, we find that farmers' self-reported symptoms have very weak associations with actual poisoning.

Regression analysis of blood tests reveals a lower incidence of poisoning for farmers who avoid the most toxic pesticides and use protective items. We also find very large provincial differences in poisoning incidence after we control for individual factors. Our results highlight the potential importance of negative externalities, and suggest that future research on pesticide-related damage should include information on local water, air and soil contamination.
\end{abstract}




\section{Introduction}

Indiscriminate use and improper handling of synthetic pesticides in agriculture have caused serious problems for human health in many developing countries during the past three decades. However, the true extent of the problem is hard to determine for a variety of reasons. Farmers with mild pesticide poisoning often do not report it because treatment services are costly or inaccessible, or because they fear losing their jobs. Health care professionals in rural areas often fail to correctly diagnose poisoning, as many of the related symptoms are quite general in nature (e.g., headaches, dizziness, vomiting) (FAO, 2001). Fragmentary international evidence also indicates that pesticide poisoning is underreported in clinical data. The World Health Organization (WHO) and the United Nations Environment Program (UNEP) estimate that pesticide poisoning injures between one and five million agricultural workers per year (World Resources Institute, 1998). At least 20,000 workers die from exposure every year, the majority in developing countries (WHO, 1990; Kishi et al., 1995; Pimental et al., 1992; Rosenstock et al., 1991).

Although the health hazards of pesticides are serious, support from policy makers for remedial measures has been lukewarm in developing countries. There is widespread concern about diverting resources to alternative pest control methods when poverty, illiteracy and infant mortality are still major problems. In part, the resistance of policy makers is due to uncertainty about the severity of the problem, its sources, and suitable interventions.

Their uncertainty is understandable, since systematic studies of the health effects of pesticides are scarce. Most existing studies rely on farmers' self-reported symptoms, as appropriate pathological tests are costly and relatively difficult for many developingcountry institutions to administer. In contrast, this study of rice farmers in Vietnam uses the results of clinical exams by doctors from the Vietnam Association of Occupational Health (VINOH), along with blood tests that detect pesticide poisoning (cholinesterase inhibition due to contamination by organophosphates and carbamates). Drawing on an extensive survey of farmer characteristics, we econometrically estimate a model of 
pesticide poisoning which incorporates the toxic hazard levels of different pesticides and determinants of exposure. We also contribute to the literature on self-reporting analysis by comparing the blood test results with self-reported poisoning symptoms.

The remainder of the paper is organized as follows. Section 2 describes pesticide use trends in Vietnam, and section 3 provides a description of our survey. Section 4 presents our comparative analysis of blood test results and self-reported pesticide poisoning symptoms. We present our analysis of pesticide poisoning determinants in section 5, and conclude the paper with a discussion of implications in section 6 .

\section{Pesticide Use in Vietnam}

Like many developing countries, Vietnam has promoted the use of pesticides to expand agricultural land and increase output per acre. The Socialist Republic of Vietnam began extensive use of pesticides in the 1950s, when agricultural production was limited to cooperatives, collective farms, and state farm enterprises. During this period, pesticides were not regulated and agronomists and farmers had little knowledge of the hazards of pesticide use. Pesticide applications were done by specialized teams of 4-5 farmers, who worked in conjunction with the Plant Protection Department (PPD). The PPD supplied pesticides at subsidized prices and recommended spraying on a calendar basis, with little or no attention to field conditions (Pincus 1995; Chung and Dung, 2002).

After the land reforms of 1988 recognized farms as autonomous production units, households assumed control over all stages of production, including pesticide use. Applications doubled during the following decade (Figure 1), reaching over 40,000 tons per annum in 1998 (FAO, 2004). ${ }^{1}$

\footnotetext{
${ }^{1}$ Since 1986, the pesticide market has been liberalized, and there are currently nine state-owned and four privately-owned formulation plants in Vietnam. The government is no longer granting licenses for new formulation plants, since it has decided that excess capacity exists.
} 
Figure 1: Pesticide use in Vietnam, 1990-1999

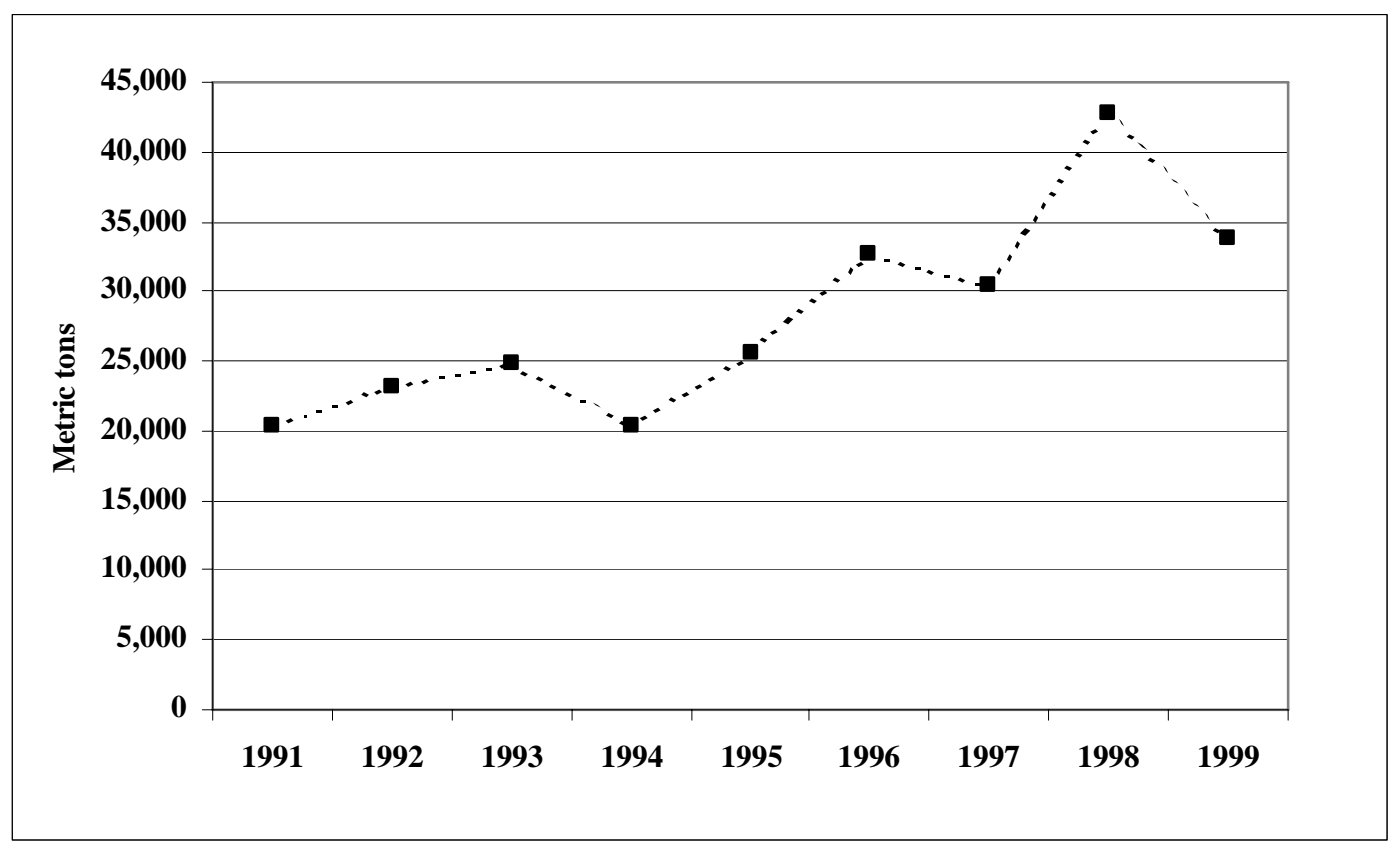

Expanded applications have been accompanied by widespread use of chemicals that are hazardous for human health and the environment. A nation-wide survey conducted by the PPD in 2000 found 2,500 $\mathrm{kg}$ of banned pesticides in use (methamidophos, DDT and other chemicals), along with 4,753 liters and 5,645 $\mathrm{kg}$ of illegally imported or counterfeit pesticides (PPD, 2000). Another survey in August 2000, among 480 farmers in four provinces in the South, found that $96.6 \%$ used pesticides more intensively than product labels recommended, and nearly $95 \%$ of farmers disposed of any remaining pesticide by pouring it into canals or ditches, reapplying it to the same crops, or spraying crops that were not identified for initial use (Huan et al., 2000).

\section{Survey Design}

The health impacts of pesticides are difficult to assess from available secondary data in most countries. Pesticide poisonings documented by health centers represent only a small fraction of actual poisonings, for two main reasons. First, only a small number of severe poisonings (mostly suicide attempts) are treated in the health care system. Many agricultural workers do not report non-lethal cases because of the cost in time or money, inaccessibility of health care services, or fear that drawing attention to themselves may result in the loss of their job. Secondly, the relatively few farmers who do seek treatment 
are often misdiagnosed because pesticide poisonings can mimic other common health problems (FAO, 2001). ${ }^{23}$

To assess the actual extent of this problem, the World Bank collaborated with the Vietnam Association of Occupational Health to study pesticide poisoning among Mekong Delta farmers in the first quarter of 2004. With 482 farmers participating, the study collected both survey and clinical data. Structured questionnaires were used to collect information on farming systems, pesticide use and practices, applicator precautions, protective measures, and self-reported poisoning symptoms. ${ }^{4}$ All participating farmers were examined by the doctors from the Vietnam Association of Occupational Health. Using clinical exam results and self-reported symptoms, the study team selected potentially-poisoned farmers for blood tests that detect acute or chronic contamination by pesticides (organophosphates and carbamates).

The medical survey covered the districts of An Phu and Chau Thanh (An Giang province), Thot Not and Vi Thanh (Can Tho province), Tan Thanh and Thu Thua (Long An province ), Cai Lay and Cho Gao (Tien Giang province), and $\mathrm{Tra} \mathrm{Cu}$ and Tieu Can (Tra Vinh province) in the Mekong Delta. The 482 surveyed farmers are almost all male ( 3 females were examined). Their ages range from 15 to 70 years, with an average age of 39. The surveyed farmers average 8 years of education; $74 \%$ report that they smoke and $48 \%$ report drinking alcoholic beverages. To minimize possible reporting bias, the surveyed farmers were assured of anonymity.

\section{Health Impairment: Self-Reported and Blood Test Results}

The survey asked farmers to report symptoms experienced after mixing and spraying pesticides. Figure 2 displays the most commonly-reported symptoms: dermal (skin irritation: 63\%), neurological (headache: 60\%; dizziness: 53\%), ocular (eye

\footnotetext{
${ }^{2}$ Hospital admission records in Vietnam attribute $11 \%$ of all poisonings to pesticide misuse: approximately 840 poisonings in 53 cities and provinces in 1999 (Poison Control Center, Vietnam Ministry of Health, 2000).

${ }^{3}$ The World Health Organization estimates that there are 50 cases of poisoning for every case reported and registered (WHO, 1990).

${ }^{4}$ The survey was designed by the World Bank team.
} 
irritation: $55 \%$ ), and respiratory (shortness of breath: $45 \%){ }^{5}$ Most (88\%) of the surveyed farmers reported multiple symptoms, with an average of 4 and a maximum of 9 . Among farmers reporting symptoms, $82 \%$ attributed them to pesticide use.

Figure 2: Self-reported health impairments after using pesticides (\%)

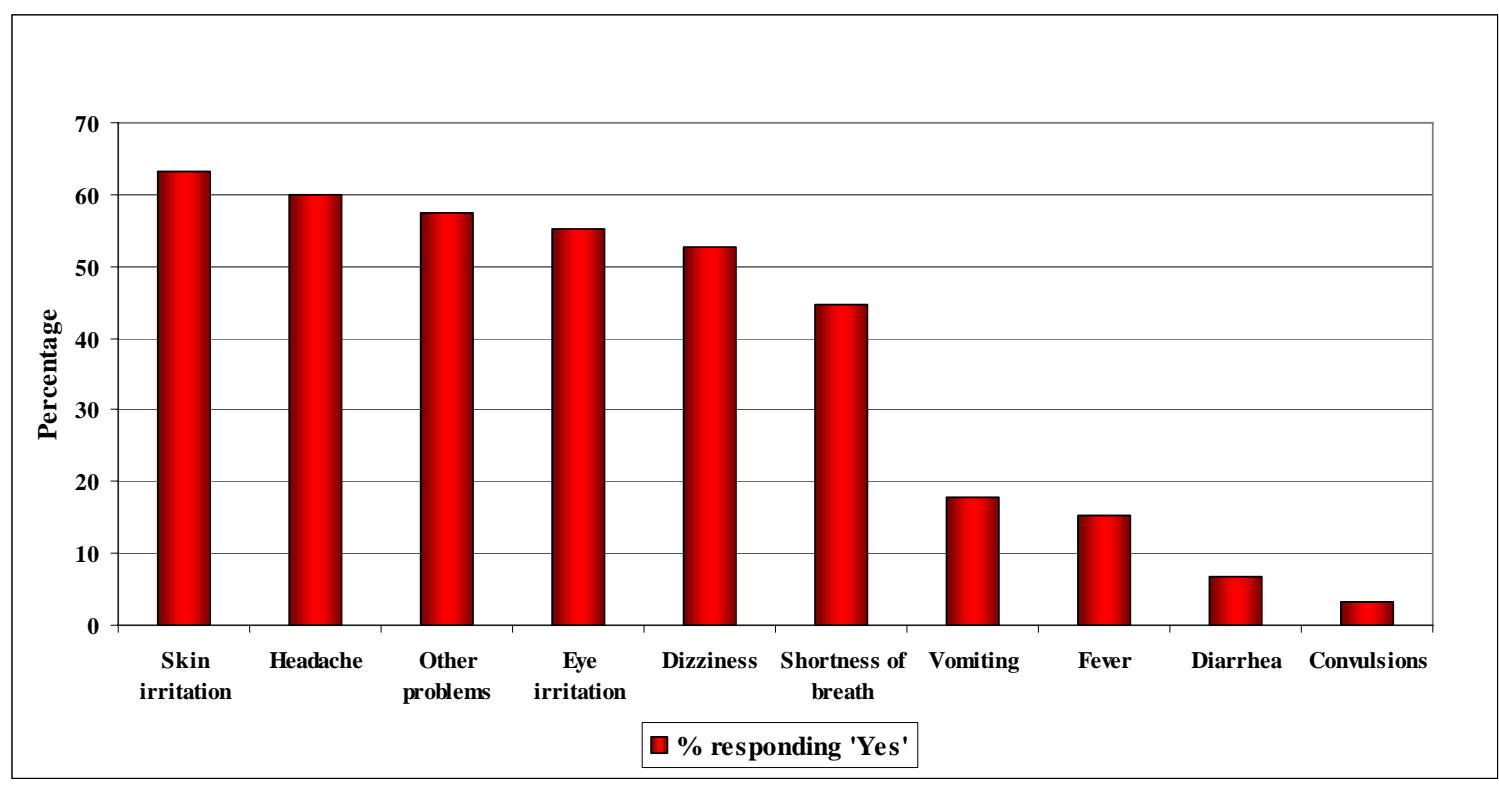

To assess the validity of self-reported symptoms, the study included a team of doctors $^{6}$ who screened and tested the farmers for pesticide exposure. The initial screening used several key indicators for potential pesticide exposure - prevalence of skin diseases, abnormal blood pressure, respiratory disease, and heart disease. The tests revealed a high prevalence of skin disease (41\%) and abnormal blood pressure (18\%), with $3 \%$ incidence for reported respiratory disease and $1 \%$ for heart disease.

Building upon the initial screening exam, the medical team administered blood tests to 190 farmers to check for cholinesterase enzyme inhibition from exposure to

\footnotetext{
${ }^{5}$ Other studies in Vietnam report similar findings for self-reported ailments. In a study of 369 tea farmers, Xuyen et al. (1998) report incidence rates for headaches (44\%), nausea (15\%), skin irritation (58\%) and dizziness (24\%). Du and Phoung (2003) report the incidence of headaches $(60 \%)$ and dizziness $(27 \%)$; and a survey of 1,982 farmers by Hon Tu et al. (1999) reports the incidence of fatigue (26\%), skin irritation $(20 \%)$, headaches $(20 \%)$, dizziness $(20 \%)$ and eye irritation $(4 \%)$.

${ }^{6}$ Staff doctors from the Centre of Occupational and Environmental Health (COEH) of the Vietnam Association of Occupational Health (VINOH), Hanoi, Vietnam.
} 
organophosphate and carbamate pesticides. ${ }^{7}$ Selection criteria included symptoms of cholinesterase inhibition such as headache, nausea, drooling, fatigue, dizziness, tearing, pin-point pupils, shortness of breath, muscle weakness and convulsion. In each case, a $0.4 \mathrm{ml}$ blood sample drawn from the farmer's fingertip was used to test the level of active cholinesterase enzyme (AchE) in red blood cells and plasma. The blood samples were analyzed at the Central Medical Laboratory of Tien Giang province, following the guidelines of the technical manual on Occupational and Environmental Health of Vietnam (1993). The results, displayed in Figure 3, indicate a high prevalence of pesticide poisoning (35\%), with a large proportion showing chronic poisoning $(21 \%)$.

\section{Figure 3: Medical blood test results for the detection of acute and chronic pesticide poisoning}

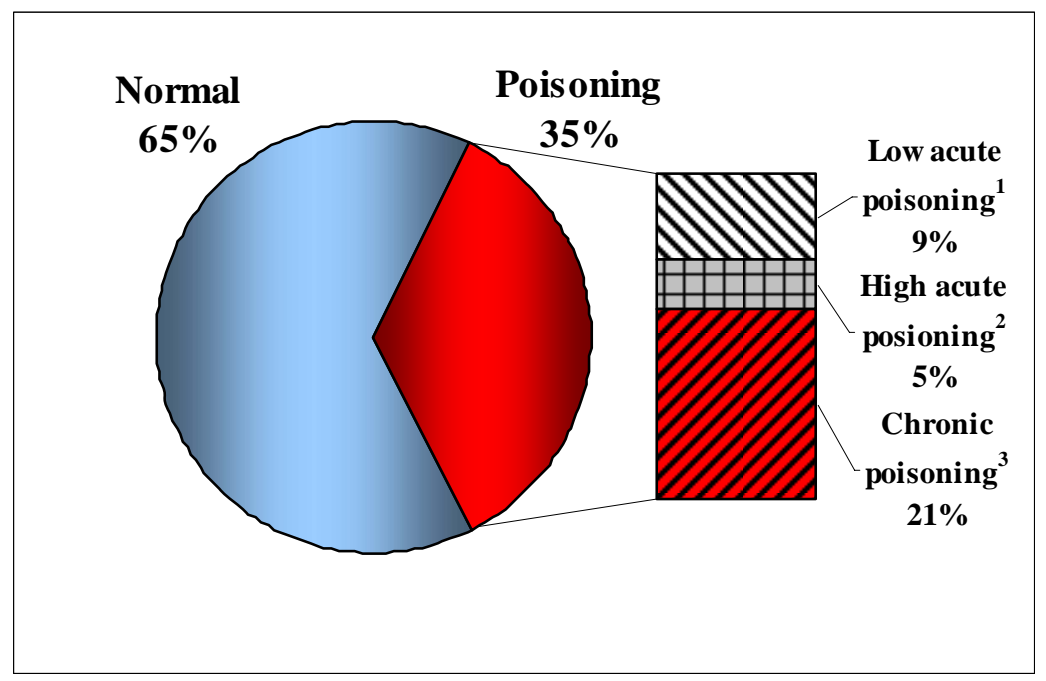

1 - Reduction of numerical value of AchE in red cells and in plasma $>25 \%$;

2 - Reduction of numerical value of AchE in red cells and in plasma $>33 \%$;

3 - Reduction of numerical value of AchE in red cells $>66 \%$.

We use the test results to assess the relationship between self-reported symptoms and medically-verified pesticide poisoning. First, we calculate a correlation coefficient for each self-reported symptom against the blood test results. The highest correlation in the

\footnotetext{
${ }^{7}$ Epidemiological studies have linked carbamates and organophosphates with fetal death, hormonal changes, DNA damage, birth defects, and abnormal sperm, ovaries and eggs. In addition, organophosphates, as a class of insecticides, have been linked with Non-Hodgkin's lymphoma, leukemia, and lung cancer. In children organophosphates have been linked to aplastic anemia, the failure of the bone marrow to produce blood cells, and leukemia. Children with asthma may have severe reactions to organophosphates in particular (Zahm et al, 1997). See Appendix I for details on the blood (cholinesterase) test.
} 
whole set is only $\rho=0.17$. In a second exercise, we calculate the correlation of the blood test result against an index of equally-weighted symptoms that are commonly associated with blood poisoning (convulsions, diarrhea, dizziness, eye irritation, headaches, shortness of breath and vomiting). The composite correlation is even weaker: $\rho=0.05$. We conclude that our evidence does not support the use of self-reported symptoms as indicators of actual pesticide poisoning. Given the high incidence of poisoning in the sample, however, our results strongly support regular medical testing for farmers who are exposed to highly- or moderately-toxic organophosphate and/or carbamate pesticides.

\section{Determinants of Cholinesterase Inhibition}

Using the blood cholinesterase test results, we conduct a regression analysis to identify the major determinants of pesticide poisoning. According to the medical literature, the types and severity of cholinesterase inhibition symptoms depend on the toxicity of the pesticide, the amount of pesticide involved in the exposure, the route of exposure, and the duration of exposure (Extension Toxicology Network, 2004). The health effects of pesticide use can often be reduced significantly by appropriate use of protective items such as gloves, hats, jackets, eye glasses or masks (Cropper, 1994). A priori, we would expect farmers' self-protective behavior to depend on their perception of risk, along with the quality of their information about safe handling of pesticides. Taking these factors into account, we specify and estimate the following regression model with dummy variables to control for provincial differences.

\section{POISONING $=\mathrm{f}($ PESTAMT, PWHOIab, PWHOII, PWHOIII, PWHOU, PTRAIN, NPROTECT, IPMD, Provincial Dummies*)}

where

$\begin{array}{ll}\text { POISONING } & =1 \text { if acute/chronic poisoning indicated by cholinesterase test, } 0 \text { otherwise; } \\ \text { PESTAMT } & =\text { total amount of pesticides applied (kilograms); } \\ \text { PWHOIab } & =\% \text { of pesticides classified as highly hazardous (WHO category Ia or Ib); } \\ \text { PWHOII } & =\% \text { of pesticides classified as moderately hazardous (WHO category II); } \\ \text { PWHOIII } & =\% \text { of pesticides classified as slightly hazardous (WHO category III); } \\ \text { PWHOU } & =\% \text { of pesticides with no significant hazard in normal use (WHO category U); } \\ \text { PTRAIN } & =1 \text { if trained in safe handling of pesticides, } 0 \text { otherwise; } \\ \text { NPROTECT } & =\text { protective items used ( } 1=\text { if more than } 2,0 \text { otherwise); } \\ \text { IPMD } & =1 \text { if Integrated Pest Management techniques employed, } 0 \text { otherwise; }\end{array}$

* Dummy for Tra Vinh province dropped to permit estimation. 
We estimate a probit model that incorporates adjustments for heteroskedasticity. The results, reported in Table 1, provide only weak support for the standard explanatory model of individual exposure. Three individual variables are significant (pesticide amount, high-hazard $\%$ and use of protective items), however the first has a perverse sign. ${ }^{8}$ Neither training in safe-handling nor use of IPM techniques has the expected effect. However, we find strong provincial effects. Controlling for individual circumstances, the incidence of poisoning in Can Tho and Tien Giang is much lower than in Tra Vinh (excluded) and An Giang.

Table 1. Determinants of blood cholinesterase inhibition

\begin{tabular}{lcc}
\hline & Model 1 & Model 2 \\
\hline Variable & Coefficient & Coefficient \\
\hline PESTAMT & $-0.098^{* *}$ & $-0.105^{* *}$ \\
& $(-2.09)$ & $(-2.24)$ \\
PWHOIab & $0.039^{* * *}$ & $0.030^{* *}$ \\
& $(2.51)$ & $(2.08)$ \\
PWHOII & 0.003 & \\
& $(0.46)$ & \\
PWHOIII & 0.008 & \\
& $(1.19)$ & \\
PWHOU & 0.006 & \\
& $(0.90)$ & \\
PTRAIN & 0.262 & \\
& $(1.22)$ & $-0.440^{*}$ \\
NPROTECT & $-0.443^{*}$ & $(-1.91)$ \\
& $(-1.86)$ & \\
IPMD & 0.043 & \\
& $(0.19)$ & \\
An Giang & -0.118 & $-0.628^{* *}$ \\
& $(-0.33)$ & $(-2.39)$ \\
Can Tho & $-0.821^{* *}$ & \\
& $(-2.49)$ & \\
Long An & -0.449 & $(-2.41)$ \\
& $(-1.36)$ & 187 \\
Tien Giang & $-0.841^{* * *}$ & $-0.605^{* *}$ \\
& $(-2.58)$ & \\
\hline & & \\
Observations & 187 & \\
& & \\
\hline
\end{tabular}

* - significant at the $1 \%$ level;

** - significant at the $5 \%$ level

$* * *$ - significant at the $10 \%$ level

\footnotetext{
${ }^{8}$ We also estimated a regression for pesticide use, with the following right-hand variables: farm size, IPM and pesticide training, actual use of IPM, farmer's age, education, and income and provincial dummies. The significant variables were farm size, farmer's age, and province dummies for An Giang, Long An and Tien Giang. Farm size has the largest impact $(\varepsilon=0.93)$, suggesting that pesticide use is primarily driven by scale.
} 
Our results suggest that farmers in Vietnam can reduce their individual risks by employing lower-hazard pesticides and using protective items. However, the strong provincial effects may indicate significant externality problems as well. Pervasive contamination from others' pesticide use may poison individual farmers, even if their own practices are prudent. Future research on pesticide poisoning should test this proposition by including measures of contamination of local surface water, ground water, air and soil.

\section{Summary and Conclusions}

In this paper, we have assessed the incidence and determinants of pesticide poisoning among rice farmers in Vietnam's Mekong Delta. We believe that our results are of particular interest because they rely on explicit medical tests for poisoning, rather than conventional self-reporting of symptoms by farmers. The medical tests suggest that the incidence of poisoning from exposure to organophosphates and carbamates is quite high in Vietnam. Using the medical test results as benchmarks, we find that farmers' selfreported symptoms have very weak associations with actual poisoning. Both the incidence of poisoning and farmers' own apparent inability to distinguish its symptoms from other health problems suggest that regular checkups and blood tests should be conducted for those who load, mix, or apply highly or moderately-toxic organophosphate and carbamate pesticides.

In a regression analysis of blood cholinesterase test results, we find a lower incidence of poisoning for farmers who avoid the most toxic pesticides and use protective items. However, our results are either perverse or insignificant for other individual factors that are conventionally believed to reduce risk: Total pesticide applications, use of IPM techniques, and training for safe handling of pesticides. In contrast, we find very large provincial differences in poisoning incidence after we control for individual factors. Our results highlight the potential importance of negative externalities, and suggest that future research on pesticide-related damage should include information on local water, air and soil contamination. The potential importance of these factors suggests that collective 
measures may provide an important complement to individual actions in reducing farmers' exposure to pesticide hazards.

\section{References}

Chung, D. K. and K. T. Dung. 2002. Pest Management in Rice Production in Vietnam: A Socio-economic Assessment. Hanoi: Nha Xuat Ban Nong Nghiep.

Cropper, M. 1994. Economic and Health Consequences of Pesticide Use in Developing Country Agriculture: Discussion. American Journal of Agricultural Economics 76: 605-607.

Du, L. N. T. and N. T. Phoung. 2003. Real Situation of Preservation, Use and Residues of Pesticides in Honey Grass in An Vy, Khoai Chau, Hung Yen province. The $1^{\text {st }}$ International Scientific Conference, Hanoi, Vietnam, pp. 275.

Extension Toxicology Network (ECOTOXNET). 2004. Cholinesterase Inhibition. Toxicology Information Brief. Cornell University. Available at: http://pmep.cce.cornell.edu/profiles/extoxnet/TIB/cholinesterase.html

FAO. 2001. Farmer Self-Surveillance of Pesticide Poisoning Episodes: Report on One Month Pilot: August 15-Sept 15, 2000. FAO Programme for Community IPM in Asia, Field Document.

FAO. 2004. FAO-STAT. Statistics downloaded for Vietnam. Available at: http://apps.fao.org/default.jsp.

Hon Tu, N. et al. (1999) Report of investigation for working condition and female workers' health in agricultural production. Ministry of Health, Hanoi.

Huan, N. H. and L. V. Thiet et al., 2000. Results of Survey for Confidence, Attitude and Practices in Safe and Effective Use of Pesticides.

Kishi, M., N. Hirschhorn, M. Qjajadisastra, L. N. Satterlee, S. Strowman and R. Dilts. 1995. Relationship of Pesticide Spraying to Signs and Symptoms in Indonesian Farmers. Scandinavian Journal of Work \& Environmental Health 21: 124-133.

Pimental, D., Acquay H., Biltonen, M., 1992. Environmental and Economic Costs of Pesticide Use. Bioscience 42, 750-60.

Pincus, J. 1995. Pesticide Policy Survey. Unfinished report. FAO Intercountry Programme for IPM in Rice in South and Southeast Asia, Hanoi. 
Poison Control Center, Vietnam Ministry of Health, 2000. Statistics reported in Vietnam Country Report, The $7^{\text {th }}$ GINC Conference, Tokyo, April 18-21, 2001. Available at: http://www.nihs.go.jp/GINC/meeting/7th/7profile/vietnam.pdf

PPD (Plant Protection Department), 2000, Report on Results of Nation-wide Inspection of Pesticide Regulation Enforcement in 2000, Large-scale Inspection Meeting for 2000 in Hanoi, 31 October 2000.

Rosenstock, L., Keifer, M, Daniell, W. E, McConnell, R., Claypoole, K. 1991. Chronic Central Nervous System Effects of Acute Organophosphate Pesticide Intoxication. Lancet 338: 223-227.

Xuyen, K., N. C. Hoi and P. Q. Trung. 1998. Occupational Environment and Skin Diseases in Pesticide Exposed Subjects in some Tea Farms in Vietnam. Presentation given at the Third National Scientific Conference on Occupational Health, December 45, 1998. Hanoi.

World Health Organization (WHO). 1990. Public Health Impact of Pesticides Used in Agriculture, 1990.

World Resources Institute, UNEP, UNDP, the World Bank. 1998. Environmental Change and Human Health. World Resources 1998-99.

Zahm, S. H., Ward, M. H., Blair, A., 1997. Pesticides and cancer. In: Occupational Medicine: State of the Art Reviews. Vol. 12: Pesticides (Keifer M, ed). Philadelphia: Hanley and Belfus, Inc., 269-289. 


\section{Appendix I: Cholinesterase Test}

Cholinesterase is one of many important enzymes needed for the proper functioning of the nervous systems of humans, other vertebrates, and insects. Certain chemical classes of pesticides, such as organophosphates (OPs) and carbamates (CMs), kill undesirable insect pests by interfering with, or 'inhibiting', cholinesterase. While cholinesteraseinhibiting pesticides are intended for insects, they can also be poisonous to humans in some situations. Human exposure to cholinesterase-inhibiting pesticides can result from inhalation, ingestion, or eye or skin contact during the manufacture, mixing, or applications of these chemicals. Anyone exposed to cholinesterase-inhibiting pesticides can develop lowered cholinesterase levels. Signs and symptoms of cholinesterase inhibition from exposure to CMs or OPs include the following:

1. In mild cases (within $4-24$ hours of contact): tiredness, weakness, dizziness, nausea and blurred vision;

2. In moderate cases (within 4 - 24 hours of contact): headache, sweating, tearing, drooling, vomiting, tunnel vision, and twitching;

3. In severe cases (after continued daily absorption): abdominal cramps, diarrhea, muscular tremors, staggering gait, pinpoint pupils, hypotension (abnormally low blood pressure), slow heartbeat, breathing difficulty, and possibly death, if not promptly treated by a physician.

The cholinesterase test is a blood test used to measure the effect of exposure to cholinesterase-inhibiting insecticides. Both plasma (or serum) and red blood cell (RBC) cholinesterase are generally tested. Physicians find plasma cholinesterase readings helpful for detecting the early, acute effects of organophosphate poisoning, while red blood cell readings are useful in evaluating long-term, or chronic, exposure.

The purpose of checking cholinesterase levels is to alert exposed people to any change in the level of this essential enzyme before it can cause serious illness. The interpretation of cholinesterase test results should be done by a physician. A 15- to 25-percent depression in cholinesterase indicates that slight poisoning has taken place. A 25- to 35-percent drop signals moderate poisoning, and a 35 - to 50-percent decline indicates severe poisoning. 